\title{
OBSTÁCULOS EPISTEMOLÓGICOS DE BACHELARD E CONSTRUTIVISMO SISTÊMICO: REQUESTIONAMENTOS AOS DIREITOS HUMANOS
}

\section{Luís Gustavo Gomes Flores ${ }^{1}$}

Resumo: A observação do tema dos Direitos Humanos entre inúmeros avanços e retrocessos sugere enfrentar o problema de pesquisa que indaga: Qual a relevância de estudos a partir de uma epistemologia de caráter filosófico, sociológico e construtivista para os Direitos Humanos? Assim, tem-se como objetivo lançar um olhar diferente das concepções tradicionais dos Direitos Humanos. Para tanto, o método utilizado, foi o sistêmico construtivista, equacionando reflexões filosóficas-sociológicas e construtivistas do Direito. Como resultado se constatou a relevância de realizar novas observações no Direito e da superação, antes de tudo, dos próprios obstáculos para a realização dos Direitos Humanos na Sociedade Complexa.

Palavras-chave: Obstáculo Epistemológico; Bachelard; Armadura Dogmática do Direito; Construtivismo Sistêmico; Direitos Humanos.

\section{EPISTEMOLOGICAL OBSTACLES OF BACHELARD AND SYSTEMIC CONSTRUCTIVISM: REQUIREMENTS FOR HUMAN RIGHTS}

\begin{abstract}
The observation of the theme of Human Rights among innumerable advances and setbacks suggests to face the research problem that asks: What is the relevance of studies from a philosophical, sociological and constructivist epistemology for Human Rights? Thus, the objective is to cast a different perspective on the traditional conceptions of Human Rights. For this, the method used was the systemic constructivist, equating philosophical-sociological and constructivist reflections of the Law. As a result, the relevance of making new observations in the Law and of overcoming, first and foremost, the obstacles to the realization of Human Rights in the Complex Society.
\end{abstract}

Keywords: Epistemological Obstacle; Bachelard; Dogmatic Armor of Law; Systemic Constructivism; Human rights.

\section{INTRODUÇÃO}

Diante dos muitos estudos e avanços já realizados sobre os Direitos Humanos, bem como, também de um cenário alarmante de violações, o presente texto tem como objetivo a tarefa de lançar um olhar diferente dos tradicionalmente desenvolvidos sobre os Direitos

\footnotetext{
${ }^{1}$ Luis Gustavo Gomes Flores: Pós-Doutor (Bolsista dedicação exclusiva - PNPD/CAPES-Turma nº: PD1400100006), Doutor e Mestre pelo Programa de Pós-Graduação em Direito (PPGD) da Universidade do Vale do Rio dos Sinos - UNISINOS - CAPES - 6, e possui graduação em Direito pela Universidade de Santa Cruz do Sul UNISC. Atualmente é Professor do Programa de Pós-Graduação em Direito da UNIJUÍ - Mestrado em Direitos Humanos. Membro do Grupo de Pesquisa Teoria do Direito (UNISINOS - Leonel Severo Rocha) e Coordenador do Projeto Desenvolvimento Humano, Transformações Sociais e Resiliência do Direito.
} 
Humanos. Percorrer sempre os mesmos caminhos pode levar sempre aos mesmos lugares e resultados. Por isso, sem desconsiderar as matrizes teóricas mais tradicionais, pretende-se desenvolver uma perspectiva mais voltada a uma reflexão epistemológica, de caráter filosófico-sociológico e construtivista do Direito, que sirva para repensar os contornos dos Direitos Humanos na atualidade. Contudo, isso exige enfrentar o seguinte problema: Qual a relevância que um estudo fora de uma perspectiva tradicional, realizado a partir de uma epistemologia de caráter filosófico, sociológico e construtivista pode dar para os Direitos Humanos? Qual a relevância que esse estudo pode ter para os Direitos Humanos?

Para tanto, o trabalho foi desenvolvido em três momentos. No primeiro ponto sobre Armadura dogmática do Direito, se apresentou os traços basilares da epistemologia jurídica predominante na Modernidade e seus obstáculos para a realização dos Direitos Humanos.

No segundo ponto, Epistemologia Contradogmática para os Direitos Humanos, busca-se acentuar a importância da superação de obstáculos internos e externos à realização dos Direitos Humanos.

No terceiro ponto Direitos Humanos e Construtivismo Sistêmico busca-se desenvolver a importância de se considerar também os Direitos Humanos em uma perspectiva pragmática, de caráter sociológico e acentuando a relevância da comunicação social na Sociedade Complexa para desenvolver estratégias que contribuam para a realização dos Direitos Humanos.

Trata-se de uma reflexão que acentua a relevância de percorrer novos caminhos e desenvolver novas observações. Uma condição para criar estratégias inovadoras para enfrentar, tanto os velhos problemas, como os novos desafios que podem ser obstáculos para a realização dos Direitos Humanos na Sociedade Complexa.

\section{ARMADURA DOGMÁTICA DO DIREITO}

Da criação da Organização das Nações Unidas (ONU) no ano de 1945, passando pela Declaração Universal dos Direitos do Homem em 1948 até o contexto da sociedade atual podemos observar muitas contribuições e avanços, tanto teóricos como práticos, para a realização dos Direitos Humanos. Contudo, por outro lado, também se percebe ainda uma elevada gama de violações a esses Direitos (PIOVESAN, 2009). 
Sabe-se que os processos evolutivos não são necessariamente lineares, contínuos e progressivos. (COMPARATO, 2010). Ocorrem em uma dinâmica de avanços e retrocessos. Isso sugere que os desenvolvimentos, sobretudo acadêmicos, nem sempre correspondem à obtenção de êxito pragmático. ${ }^{2}$ Isso pode possuir diversas causas, entre elas destaca-se aqui o fato de que a sociedade atual revela uma conjuntura complexa de perspectivas que normalmente não são consideradas e isso problematiza muito a produção de resultados em termos de efetividade da realização dos Direitos Humanos.

Mesmo Norberto Bobbio, dentro de sua linha específica de trabalho, não desprezou o olhar para o contexto social, quando reconhece que

Também os direitos do homem são, indubitavelmente, um fenômeno social. Ou, pelo menos, são também um fenômeno social: e, entre os vários pontos de vista de onde podem ser examinados (filosófico, jurídico, econômico, etc.), há lugar para o sociológico, precisamente o da sociologia jurídica. (BOBBIO, 2004, p. 33).

Aproveitando essa perspectiva, mas pretendendo desenvolver uma reflexão diferenciada das perspectivas tradicionais, convém questionar sobre os obstáculos que impediram e continuam impedindo uma melhor realização pragmática dos Direitos Humanos até o contexto atual. (PIOVESAN, 2009, p. 109), Certamente, essa questão se torna desafiadora quando se desloca a preocupação de o que se pode observar como obstáculos, para focar em como se pode observar. Essa segunda observação certamente terá grandes implicações na primeira.

A ideia aqui é observar o que foi indicado como contexto social atual, como uma forma de Sociedade Complexa ${ }^{3}$ (LUHMANN, 2007). Contudo, essa opção exige uma capacidade de observação sofisticada (MATURANA, 2000). Isso implica diretamente na tarefa de rever as reflexões sobre a forma de observação do Direito, o que pressupões uma reflexão epistemológica, sobretudo no sentido de problematizar perspectivas

\footnotetext{
2 Alguns podem discordar dessa afirmação por acharem ela muito radical, contudo esse julgamento pode ser facilmente desconstruído se for considerado os níveis de miséria que alguns povos ainda vivem em pleno século XXI, sem as condições mínimas para se ter um pouco de dignidade. Situações de seres humanos, em muitos casos crianças, que não se pode dizer que vivem, mas estão sobrevivendo. Uma sobrevivência excluída. Estão passando por fases da vida que não voltam e que não lhes permitirão serem incluídos ou ao menos estarem à margem.

${ }^{3}$ Muitas denominações são desenvolvidas por diversos autores. Sociedade em Rede, Sociedade Líquida, Segunda Modernidade, Sociedade de Risco, etc. A opção pela significação de Sociedade Complexa se justifica justamente porque tem a pretensão de ser uma semântica que compreende nela todas essas outras indicações de sociedade que de alguma forma acentuam algum aspecto específico da sociedade. Contudo, a ideia de Sociedade Complexa busca compreender e não fragmentar essa complexidade, acentuando cada um dos aspectos dependendo da observação que será elaborada em determinada circunstância (no espaço- tempo).
} 
predominantemente dogmáticas no Direito (LUHMANN, 2005).

Diante disso, surge o desafio de desenvolver um olhar diferenciado. Apesar de existir inúmeros debates sobre as mais variadas perspectivas de realização dos Direitos Humanos, entende-se que também seja importante uma reflexão epistemológica que atravesse todos os âmbitos do Direito. Embora cada ramo do Direito possua suas peculiaridades, sempre existem aspectos comuns importantes. Estar-se-á tratando de um mesmo sistema jurídico, que também pode ser compreendido como um sistema parcial da sociedade ${ }^{4}$. Essa reflexão epistemológica está na base de qualquer reflexão que envolva qualquer âmbito jurídico, inclusive os Direitos Humanos.

A sociedade aqui observada é a Sociedade Moderna ${ }^{5}$. Num contexto delineado por inúmeras mudanças que emergem com o período Pós-Segunda Guerra Mundial.

Ao emergir da Segunda Guerra Mundial, após três lustros de massacres e atrocidades de toda sorte, iniciados com o fortalecimento do totalitarismo estatal nos anos 30, a humanidade compreendeu mais do que em qualquer outra época da História, o valor supremos da dignidade humana. (COMPARATO, 2010, p. 68)

Nessa linha de raciocínio, podemos considerar dois grandes marcos para a proteção dos Direitos Humanos: a criação da ONU (1945) e a Declaração Universal dos Direitos do Homem (1948), como bem acentua Comparato:

\begin{abstract}
A Declaração Universal, aprovada pela Assembleia Geral das Nações Unidas em 10 de dezembro de 1948, e a Convenção Internacional sobre a prevenção e punição do Críme de genocídio, aprovada um dia antes também no quadro da ONU, constituem os marcos inaugurais da nova fase histórica, que se encontram em pleno desenvolvimento (COMPARATO, 2010, p. 68).
\end{abstract}

Um momento em que os Direitos Humanos ganham visibilidade e maior relevância no âmbito internacional. Um período em que se começa a rever os contornos admitidos até então no Direito. Quando se constata o esgotamento de uma racionalidade que forjou toda a Modernidade. Essa razão moderna que se desenvolve no âmbito do Direito como positivismo jurídico e na continuidade também como um normativismo jurídico, constituiu a base do

\footnotetext{
${ }^{4}$ Isto significa que apesar do Direito constituir parte da sociedade, sobretudo porque produz comunicação social, ele também possui suas peculiaridade, sua identidade o que implica em uma comunicação que além de ser social ela é jurídica, determinada por certos limites que possibilitam compreender esse âmbito de produção de conhecimento e comunicação como o sistema social do Direito.

${ }^{5}$ Que corresponde à concepção de uma sociedade funcionalmente diferenciada e também pode ser compreendida como uma forma de Sociedade Complexa. Um sistema social que compreende uma multiplicidade de possibilidades de produção de sentidos diferentes.
} 
Direito na Modernidade, e da mesma forma se mostrou insuficiente para garantir certo desenvolvimento e emancipação humana. Assim, emerge uma tendência na forma de operacionalizar o Direito que fica conhecida como Pós- positivismo ${ }^{6}$ (DINIZ; MAIA, 2006).

Apesar dos esforços para transcender e superar as configurações jurídicas da razão moderna, ela permaneceu discretamente imbricada no pensamento e na prática jurídica brasileira. Muitos pressupostos dessa razão moderna permaneceram inclusive em teorias críticas, que apesar de certa intenção de superação do positivismo, não conseguiram se livrar totalmente dos pressupostos modernos que muitas vezes permaneceram de forma implícita e subjacente na ordem do discurso (ROCHA, 2003, p. 57).

Esses traços da racionalidade moderna que constituíram os contornos do positivismo e normativismo jurídico foram conservados em múltiplas perspectivas teóricas ${ }^{7}$. Foram mantidas, independente dos contornos assumidos, através de técnicas analíticas de articulação de princípios, axiomas e proposições, enquanto operacionalizações jurídicas aparentemente descompromissadas com qualquer orientação própria de um sistema teórico específico, estando mais ligada a uma espécie de sistematização técnica de todos esses elementos, sem abandonar o que talvez seja o traço mais forte: uma postura excessivamente conservadora, voltada à fragmentação e simplificação. Essa perspectiva jurídica ainda atualmente é conhecida como dogmática jurídica. (SUPIOT, 2007).

A dogmática jurídica, como a própria denominação já sugere, revela um conhecimento assentado em posturas fixas, normalmente consideradas inquestionáveis. Uma técnica jurídica, linear e simplificadora, que se justifica pela operacionalização que proporciona. Uma operacionalização redundante, normalmente, da articulação de um conjunto de axiomas que é reproduzida, e assim difundida, cotidianamente nos tribunais, como parte da estratégia de certa manipulação do sentido jurídico.

Do positivismo legalista e para além do normativismo jurídico, pode-se observar uma base de racionalidade fortemente assentada em uma perspectiva analítica e objetivista, voltada à construção formal de uma linguagem jurídica rigorosa. Uma epistemologia que

\footnotetext{
${ }^{6}$ Um movimento na cultura jurídica mundial de constatação das insuficiências do positivismo e da necessidade de contemplar na operacionalização do Direito, aspectos que acentuassem valores elevados como os direitos fundamentais como reconhecimento da importância dos Direitos Humanos.

${ }^{7}$ Aqui se menciona tanto o termo Positivismo, como Normativismo, como forma de fazer referência a esse fenômeno compreendido de forma mutável e multifacetado, podendo assumir inúmeros contornos, desde um positivismo legalista que confundia direito com lei, como uma postura que acentua a estrutura normativa, mas a partir de uma teoria mais elaborada, como foi a herança deixada por Kelsen com os pressupostos e categorias desenvolvidos na Teoria Pura do Direito (Kelsen, 2006).
} 
conduz a uma instrumentalização do conhecimento jurídico estruturado discursivamente através de uma lógica formal, capaz de transportar ideologicamente intenções ocultas na pretensão mítica da neutralidade. Não foi em vão que um dos pressupostos kelsenianos ${ }^{8}$ da Teoria Pura do Direito foi o afastamento, numa perspectiva epistemológica, de aspectos valorativos, políticos ou ideológicos, da tarefa de conhecer e compreender o Direito (KELSEN, 2006). Um ideal de pureza como estratégia para buscar e sustentar uma neutralidade que nunca existiu.

Assim é como se a dogmática criasse uma armadura dogmática (FLORES, 2014) que protege a lógica da sua racionalidade contra toda possibilidade de esclarecimento sobre perspectivas de observação por ela negligenciada. Dessa forma a dogmática jurídica se fecha em uma redundância viciosa, sem saída. Com isso, diante da complexidade contemporânea o Direito sustenta uma cegueira jurídica criada por uma estratégia epistemológica de conservação da estabilidade dogmática, uma armadura epistemológica que impede que se construa internamente no Direito condições favoráveis à assimilação do "novo".

Essa Armadura Dogmática do Direito (FLORES, 2014) constitui uma forma de observar e operacionalizar as estruturas jurídicas através de estratégias que são predominantemente conservadoras, criando assim certas barreiras em relação à possibilidade de mudanças efetivas. Uma metáfora sobre a forma de operacionalização do Direito que faz referência a algo do passado, arcaico, que permite movimentos limitados e lentos. Uma estrutura que na atualidade seria em grande medida, considerada pesada e obsoleta. Assim, tem-se um Direito pesado, lento e com movimentos restritos, que correspondem a uma "produção de sentido altista". O problema da dogmática jurídica não é a repetição em si, mas o fato dessa conservação ser radical, começando a gerar problemas para à sociedade, na medida em que a forma de produção de respostas jurídicas passa a se mostrar insuficiente às demandas de um ambiente social altamente dinâmico e complexo.

Os Direitos Humanos não estão livres dessa herança epistemológica da modernidade. Principalmente porque não devem ser implementados apenas em relações notadamente internacionais. São traduzidos em legislações mais específicas de cada Estado. Será aí que os Direitos Humanos deverão se realizar: em todas as dimensões da teoria e prática jurídica cotidiana. Os Direitos Humanos inscritos em toda a estrutura legislativa como Direitos Fundamentais, devem ser considerados em todas as circunstâncias do universo social e

\footnotetext{
${ }^{8}$ A matriz normativista foi a matriz predominante na modernidade (ROCHA, 2003, p. 185).
} 
jurídico (COMPARATO, 2010, p. 70-71). Não raro nesses espaços é que predomina a perspectiva dogmática. São nesses espaços também que a dogmática jurídica se torna um problema para a realização dos Direitos Humanos (bem como, do Direito como um todo). Por esse motivo se torna relevante pensar epistemologicamente formas de transcender esse obstáculo.

Para aprimorar as estruturas jurídicas é preciso transpor essa espécie de "armadura" que parece funcionar como uma estratégia para obstaculizar qualquer possibilidade de mudança que possa gerar reflexão e que eventualmente possa resultar em questionamentos de seus fundamentos intocáveis (LUHMANN, 1985, p. 120). ${ }^{9}$

Assim, considera-se um grande desafio para o Direito desenvolver a capacidade de observar diferentes possibilidades de observar para transpor as barreiras colocadas pela armadura dogmática do Direito. Nesse sentido, Bachelard nos fornece uma importante contribuição, indicando a necessidade de compreender algumas limitações como obstáculos ao desenvolvimento de um novo conhecimento e a partir daí buscar transcendê-los.

\section{EPISTEMOLOGIA CONTRADOGMÁTICA PARA OS DIREITOS HUMANOS ${ }^{10}$}

Um dos grandes desafios para o Direito na atualidade é desenvolver a capacidade de observar para transpor as barreiras colocadas pela armadura dogmática do Direito. Pois, apesar de estarmos no século XXI, o Direito parece ainda se manter imune aos avanços epistemológicos já desenvolvidos em outros âmbitos do conhecimento.

Embora o Direito ainda preserve, mesmo de forma imperceptível, uma forte influência do paradigma moderno (através dos traços basilares do normativismo jurídico subjacentes em uma dogmática jurídica fechada), inúmeros avanços epistemológicos já foram desenvolvidos em diversos âmbitos do conhecimento. Contudo, observa-se que apesar disso, diversas mudanças epistemológicas não foram devidamente observadas na operacionalização do Direito, quando muito assimiladas, e muito menos geraram qualquer

\footnotetext{
${ }^{9} \mathrm{Na}$ linha dessa reflexão, convém observar que uma mudança nas estruturas dogmáticas provavelmente deve ser desencadeada por algo diferente da dogmática, o que já pode ser um aspecto suficiente para gerar um rechaço (defensivo) por parte da própria dogmática.

${ }^{10}$ Para tanto, o trabalho foi desenvolvido em três momentos. No primeiro ponto sobre Epistemologia Jurídica e Direitos Humanos, se apresentou os traços basilares da epistemologia jurídica predominante na Modernidade e seus obstáculos para a realização dos Direitos Humanos.
} 
mudança no sentido de obter algum aprimoramento epistemológico interno.

Um desenvolvimento significativo no âmbito da epistemologia, por exemplo, surge com Gaston Bachelard, que começa a iluminar nossos caminhos ao mencionar que

\begin{abstract}
Quando se procuram as condições psicológicas do progresso da ciência, logo se chega à convicção de que é em termos de obstáculos que o problema do conhecimento científico deve ser colocado. E não se trata de considerar obstáculos externos, como a complexidade e a fugacidade dos fenômenos, nem de incriminar a fragilidade dos sentidos e do espírito humano: é no âmago do próprio ato de conhecer que aparecem, por uma espécie de imperativo funcional, lentidões e conflitos. É aí que mostraremos causas de estagnação e até de regressão, detectaremos causas de inércia às quais daremos o nome de obstáculos epistemológicos (BACHELARD, 1996, p. 17).
\end{abstract}

Um autor a frente de seu tempo, que já começa a introduzir a importância de uma observação da complexidade, desafiando a lógica de continuidade no aprimoramento do conhecimento científico. Num passado que remonta os anos de 1928 e 1938 a contribuição teórica de Bachelard já desmistificava muitas ficções no âmbito epistemológico (ROCHA; PEPE, 2007, p. 40).

Tecendo fortes críticas aos pressupostos advindos, tanto do racionalismo como do empirismo, se opondo às crenças teóricas ingênuas e negando qualquer generalização simplificadora ou pretensão de conhecimento absoluto encerrado em compartimentos rigidamente isolados, Bachelard (1996, p. 17) rompe com a lógica progressiva e contínua na construção do conhecimento.

Propõe uma ruptura epistemológica com a crença em uma linearidade evolutiva que significava uma estabilidade conservadora na observação do mundo. ${ }^{11}$ Em outras palavras, ao propor uma necessária ruptura epistemológica, como condição para o avanço do conhecimento científico, estava simultaneamente indicando a importância de buscar a superação do que ele denominou de obstáculos epistemológicos. Uma noção que está no centro da reflexão sobre o progresso da ciência e passa pelo próprio processo de construção do conhecimento. Bachelard consegue observar a complexidade que envolve a produção do conhecimento científico, em especial a sua dimensão psíquica. De certa forma, Bachelard identifica, além dos desafios de uma complexidade externa ao observador, também a existência de certa complexidade e seus obstáculos internos (BACHELARD, 1996, p. 111).

Compreende que alguns obstáculos relevantes estão internamente imersos no

\footnotetext{
${ }^{11}$ Com isso também acaba por desconstruir a concepção de correspondência entre evolução e progresso que revela também uma forma de causalidade linear. (BACHELARD, 1996, p. 18-19).
} 
processo de produção do conhecimento científico. Tais obstáculos restringem a forma de Observar, impedindo que se possa construir de maneira lúcida um conhecimento científico mais adequado aos contornos do contexto social contemporâneo. $\mathrm{O}$ resultado poderia, em grande medida, se revelar através de conhecimentos que se mostrem insatisfatórios, pois na sua elaboração, talvez não se tenha considerado aspectos necessários. Tais aspectos talvez fiquem escondidos em dogmas que se colocam como barreira para a produção de um conhecimento potencialmente evolutivo.

Nesse sentido, poderíamos compreender que um dos grandes desafios na construção do conhecimento reside em desenvolver o conhecimento sobre como conhecer, de forma a não se manter restritos aos obstáculos epistemológicos e procurar então construir algo relevante. ${ }^{12}$ Poderíamos pensar a mesma questão na perspectiva de aprendizado. Não basta aprender, mas sim aprender da melhor forma possível e para tanto é preciso também aprender a aprender (MORIN, 2002, p. 29).

Aqui se pode constatar a grande importância que tem a noção de observação (LUHMANN, 2009, p. 152). Tudo que se compreende ou se concebe como realidade é fruto de uma observação. A realidade ou limites na construção do conhecimento serão tão relevantes ou adequados quanto foi a capacidade de desenvolver uma boa observação.

Ao retomar um passado cheio de erros, encontra-se a verdade num autêntico arrependimento intelectual. No fundo, o ato de conhecer dá-se contra um conhecimento anterior, destruindo conhecimentos mal estabelecidos, superando o que, no próprio espírito, é obstáculo à espiritualização (BACHELARD, 1996, p. 17).

A carga de conhecimentos já sedimentados e suscetíveis de serem identificados como insuficientes pode ser vasta e pesada. Apesar de muitas vezes gozar de uma aceitação pacífica, é justamente isso que pode obstaculizar novas possibilidades de observações e certa evolução do conhecimento.

Muitas vezes a omissão à mudança torna-se tão pesada que os novos saberes mostram-se totalmente incompatíveis com os velhos conhecimentos. ${ }^{13}$ A superação nesse caso

\footnotetext{
${ }^{12}$ Trata-se de buscar desenvolver um conhecimento de ponta, no sentido de produzir o conhecimento mais avançado possível, considerando outros avanços para além da concepção disciplinar do conhecimento. (NICOLESCU, 2005, p. 25)

${ }^{13}$ Isso pode ser melhor observado quando observamos a quebra da lógica absoluta do "precedente", quando consideramos os contornos de eventuais problemas que possa existir na atualidade, relacionados, por exemplo, em relação às diversas e imprevisíveis possibilidades de degradação ambiental, ou em relação aos "avanços" na área de biotecnologia, novas tecnologias digitais e nanotecnologias.
} 
é ainda mais difícil, já que é preciso uma drástica ruptura epistemológica com o passado. Todo conhecimento não questionado possui uma grande chance de se constituir, em certa medida, como um obstáculo epistemológico, bloqueando novas possibilidades de questionamentos do conhecimento instituído. (MOREIRA; MASSONI, 2011, p. 77).

Hábitos intelectuais que foram úteis e sadios podem, com o tempo, entravar a pesquisa. Bergson diz com justeza: "Nosso espírito tem a tendência irresistível de considerar como mais clara a idéia que costuma utilizar com freqüência." A idéia ganha assim uma clareza intrínseca abusiva (BACHELARD, 1996, p. 19).

Todo novo conhecimento precisa ser recepcionado e isso ocorre a partir de uma perspectiva forjada em conhecimentos já instituídos. Será importante desconstruir não apenas o conhecimento que está defasado, mas sobre tudo, a sedimentação epistemológica que ele já promoveu. Tanto a abertura ao novo ou a conservação do velho não possuem em si um valor positivo ou negativo. É preciso saber equacionar esses dois aspectos a partir de uma perspectiva em um espaço-tempo específico, no sentido de garantir simultaneamente a coexistência de ambos.

Resta, então, a tarefa mais difícil: colocar a cultura científica em estado de mobilização permanente, substituir o saber fechado e estático por um conhecimento aberto e dinâmico, dialetizar todas as variáveis experimentais, oferecer enfim à razão para evoluir (BACHELARD, 1996, p. 24).

A filosofia de Bachelard propõe a tarefa de provocar uma necessária descontinuidade epistemológica como condição para o desenvolvimento do conhecimento. Nesse sentido, vem enriquecer a reflexão as palavras do filósofo Albano Marcos Bastos Pêpe,

Ao assumir a Epistemologia como uma filosofia das ciências, Bachelard o faz, opondo-se aos sistemas filosóficos tradicionais, que pensam em torno de uma filosofia finalista e fechada, que concebem a filosofia das ciências como uma espécie de síntese dos resultados gerais do pensamento científico. Sua grande preocupação está na criação de uma filosofia aberta não dogmática, não voltada para as verdades primeiras, acabadas e definitivas; uma filosofia que ultrapassa seus próprios princípios adequando-se às ciências contemporâneas (PÊPE, 2007, p. 26).

Ainda hoje, esse teórico da ruptura epistemológica nos possibilita uma reflexão emergente, que por mais óbvia que seja, deve ser reforçada permanentemente, a saber, uma ruptura a ser realizada com conhecimentos passados já considerados insuficientes.

Para tanto, é preciso saber observar. Bachelard demonstrou saber disso ao romper com a crença em uma linearidade progressiva do conhecimento, entendendo que em algum 
momento o conhecimento que já foi considerado atual e relevante (no passado), pode se mostrar defasado ou insuficiente, exigindo eventual correção, ajuste ou substituição. Enquanto para muitos a ciência era pressuposto de segurança e confiança, Bachelard faz um caminho inverso, desafiava os parâmetros comodamente estabelecidos com suas reflexões (WARAT, 2004, p. 294).

Sua contribuição permite compreender a insuficiência do Direito na produção de ruptura com conhecimentos defasados. A noção de tempo do Direito, já apontado muito bem por Ost e Rocha, que indica que o Direito ocidental atual, forjado na modernidade, ainda hoje preserva uma concepção newtoniana/kantiana de Tempo, o que implica uma defasagem e também um paralelismo temporal (ROCHA, 2003, p. 197) com a sociedade. Em que pese, possa existir outras concepções temporais mais avançadas, a dogmática jurídica consegue produzir um fechamento que isola o Direito de qualquer abertura que possa ter alguma fertilidade para mudança. A própria dogmática jurídica funciona como um obstáculo epistemológico, programado para conservar um espaço de controle e acentuação do passado.

Nesse sentido, não basta uma nova perspectiva teórica mais sofisticada, é preciso ser capaz de realizar uma ruptura, que possa ser compreendida como a abertura de uma fissura na armadura dogmática do Direito, que sustenta um status de cientificidade (um tanto artificial), como um imaginário de garantia de controle de "qualidade" do conhecimento produzido (ou autorizado).

\section{DIREITOS HUMANOS E CONSTRUTIVISMO SISTÊMICO}

Apesar da relevância de sua contribuição, Bachelard foi apenas um dos muitos autores que revelam algum percurso epistemológico que a muito tempo já transcendeu os limites restritos do pensamento moderno, mas que não teve uma recepção significativa pelo Direito corrente. Existem inúmeros trabalhos que deram excelentes contribuições para elevar a epistemologia contemporânea a um nível mais sofisticado. ${ }^{14}$ Apesar de haverem ricas perspectivas já desenvolvidas, nas mais variadas áreas, esses conhecimentos dependem de

${ }^{14}$ Fala-se em "um nível mais sofisticado" de conhecimento para fazer referência às formas de conhecimentos desenvolvidas com certa disposição para enfrentar a complexidade contemporânea a fim de evitar produções ingênuas em prol da nocividade de uma mera operacionalização cujo resultado é mais um feito simbólico. 
uma articulação na sociedade, favorável à realização de uma comunicação eficaz entre os diversos sistemas sociais.

Por isso torna-se relevante, após a abertura para a observação da complexidade através da contribuição de Bachelard, também considerar a importância de uma perspectiva sociológica. ${ }^{15}$ Torna-se relevante observar o Direito imerso na complexidade da Sociedade, considerada como um ambiente altamente complexo, dinâmico e contingencial.

É preciso colocar aqui a Sociedade Moderna no foco das observações, contudo, considerando que na perspectiva luhmanniana o que se considera como Sociedade Moderna possui correspondência com a noção de uma Sociedade Complexa ${ }^{16}$, uma sociedade funcionalmente diferenciada que revela um ambiente policontextural. Trata-se de uma forma de sociedade que compreende infinitas possibilidades de comunicações sociais entre lógicas sistêmicas distintas e auto-organizativas. Convém nessa perspectiva buscar compreender a dinâmica da auto-organização social que constitui um aspecto importante da complexidade.

Para enfrentar esse desafio a fim de abrir alguma fissura na armadura dogmática do Direito, torna-se interessante uma proposta de reflexão jurídica na linha de um construtivismo sistêmico. Uma perspectiva epistemológica de caráter sociológico que permite melhor compreender alguns aspectos da complexidade social. Assim, a Teoria dos Sistemas Sociais de Luhmann significa uma perspectiva epistemológica que permite desenvolver uma observação diferenciada das complexas relações sociais (comunicativas). Nesse viés, acentuase a importância da comunicação e da observação da complexidade, na construção de uma reflexão construtivista, caracterizada a partir de operacionalizações fundadas na consideração da distinção basilar sistema/ambiente e na concepção de não haver pressupostos absolutos e

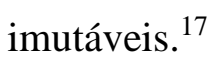

\footnotetext{
${ }^{15}$ Nesse sentido, tem-se como ponto de partida uma perspectiva sociológica de caráter sistémico. (MANSILLA; NAFARRATE, 2008, p. 67).

${ }^{16}$ Entende-se mais adequada a concepção luhmanniana de sociedade por compreender-se que compreende inúmeras outras denominações desde a noção de Pós-modernidade até as noções de Modernidade Líquida ou Sociedade do Risco, contudo indo além, concebendo todas essas particularidades dentro de uma concepção mais ampla de complexidade social. Neste sentido, a sociedade é observada enquanto um sistema social autopoiético que serve de ambiente para outros sistemas que se diferenciaram funcionalmente, entre eles o sistema jurídico.

17 "La teoría de sistema utiliza la distinción entre sistema y entorno como forma de sus observaciones y descripciones; pero para poder hacerlo debe ser capaz de distinguir esta distinción respecto a otras distinciones, por ejemplo, respecto de la teoría de la acción y, en general, para poder operar de este modo, debe formar un sistema: es decir, que en este caso, debe ser ciencia. En su aplicación a la teoría de sistemas, la concepción que hemos presentado satisface el requisito que buscábamos: el requisito de la auto implicación de la teoría. La comprensión que la teoría tiene del objeto la apremia a sacar conclusiones sobre si misma" (LUHMANN; DE GEORGI, 1993, p. 38).
} 
A partir do contexto mencionado, é possível abrirmos uma observação com base na Matriz Pragmático-Sistêmica, apresentada por Leonel Severo Rocha, que tem como ponto de partida a Teoria dos Sistemas Sociais de Niklas Luhmann (2009, p. 35). Trata- se de uma observação que considera a sociedade como um grande sistema social, constituído por diversos sistemas parciais da sociedade, que por sua vez, possuem cada um uma função e um código específico. Assim, a sociedade passa a ser observada ${ }^{18}$ como um sistema autopoiético, um sistema auto-referencial (TEUBNER, 1989), em que seus elementos são organizados, produzidos e reproduzidos pelo próprio sistema, graças a uma sequência interna de "interação circular e fechada". ${ }^{19}$ Resulta disso também, que cada um possui uma comunicação própria. O que significa que o ambiente social é constituído de diversos sistemas que são interdependentes, mas que possuem formas de produção de sentido diferentes. Assim o Direito enquanto um sistema corresponde a um contexto comum de significado (jurídico), continuamente sustentado por novas comunicações específicas.

Apesar de se tratar de comunicação social, cada sistema possui um sentido diferente, que, via de regra, não se comunica com outro diretamente. Por isso que Luhmann escreve uma obra cujo título é A improbabilidade da comunicação. Se trata de um contexto social com uma grande diversidade de possibilidades de escolhas, mas sobretudo de sentidos, que apesar de não serem totalmente compatível, possuem certa complexidade por constituírem parte estrutural de um mesmo sistema social de comunicação. Esse traço é um dos mais importantes da sociedade. Uma multiplicidade de possibilidades de sentidos diferentes.

Os acontecimentos ocorrem na sociedade a partir da comunicação. A comunicação é condição de possibilidade para a existência da sociedade. As comunicações são os elementos componentes do sistema social global (Sociedade). Daí resulta que, enquanto sistema, a sociedade é explicada como um tipo de sistema particular que compreende todas as comunicações sociais servindo de ambiente para o desenvolvimento de outros diversos sistemas, que estarão todos inter-relacionados em permanente contato (LUHMANN; DE GEORGI, 1993, p. 42). Contudo, paradoxalmente a comunicação é altamente improvável, por

\footnotetext{
${ }^{18}$ Observação é um modo específico de operação do sistema, que utiliza uma distinção para indicar um ou o outro lada de tal distinção. Ocorre uma observação cada vez que o sistema opera com base em uma distinção, ou seja, o primeiro passo para observar é observar a diferença. (CORSI; BARALDI; ESPÓSITO, 1996, p. 118). ${ }^{19}$ Convém mencionar que ao falar em interação circular e fechada, pretende-se fazer referência a um processo recursivo onde uma operação tem referência em uma operação anterior, também gera condições para operações futuras, em uma operação interna do sistema, necessária para sua auto-organização e para assegurar sua identidade, contudo não significa isolamento, mas sim condições para sua abertura.
} 
ser extremamente contingencial.

Para compreender isso é preciso considerar que a comunicação social só é possível com a ocorrência de três elementos de fundamental importância: Ato de informar, informação e compreensão (LUHMANN, 2001. p. 39). Sobre os dois primeiros elementos, quem busca comunicar alguma coisa pode ter total controle. Contudo, quanto ao terceiro elemento, ele é altamente contingêncial.

Significa que as comunicações jurídicas são produzidas na sociedade a partir de uma produção de sentido, via de regra, relativamente incompreensível para outros sistemas (e viceversa $)^{20}$. É nesse espaço complexo que os interesses se cruzam, as expectativas se revelam diferentes e as contingências quanto à compreensão das comunicações jurídicas acontecem.

Embora cada subsistema social possua seu código e autopoiese própria, eles emergiram do ambiente social, o que nos permite compreender que eles preservam em si uma identidade social, o que possibilita que participem na comunicação social geral, embora isto seja algo improvável. Significa dizer que é possível haver articulações recíprocas entre sistemas que utilizam elementos semelhantes nos atos comunicativos, sendo que a comunicação ainda dependerá também do resultado da relação com o outro sistema, ou seja, dependerá de ter havido informação, ato de informar e compreensão (LUHMANN, 2001. p. 39).

Por isso é importante considerar a Policontexturalidade em que o Direito está inserido. Muitos interesses que podem vir de outros sistemas podem colidir drasticamente com interesses comunicados em prol dos Direitos Humanos. Os sistemas funcionalmente diferenciados como, por exemplo, o Direito, a Economia e a Política (sem desconsiderar outros), se desenvolvem a partir de acoplamentos estruturais com outros sistemas igualmente diferenciados, em um desenvolvimento estrutural coordenado onde um não poderia existir sem o outro. Os sistemas sociais desenvolvem-se na sociedade e com a sociedade, de maneira conjunta, mas nem sempre de forma harmônica. ${ }^{21}$

\footnotetext{
${ }^{20}$ Relativamente incompatíveis pois existem elementos comunicativos que podem ser compartilhados por mais de um sistema, conhecidos no âmbito da Teoria dos Sistemas Sociais Autopoiéticos como sistemas simbolicamente generalizados na comunicação.

${ }^{21}$ Convém um recompor a lembrança de que na forma de sociedade estamental não havia possibilidade de acoplamento entre sistemas, pois não havia uma divisão nítida dos âmbitos sociais, ou seja, a sociedade não havia atingido um grau de desenvolvimento que permitisse uma diferenciação funcional. Em última instância o Estado aparecia como portador do acoplamento estrutural entre os sistemas político e jurídico. Após certo desenvolvimento que se afasta de um modelo estamental de sociedade e se dirige a um modelo moderno de sociedade, onde começa a ser possível tais diferenciações funcionais, consequentemente se as críticas que
} 
É justamente por não haver uma harmonia linear na evolução social é que ocorrem as violações de Direitos Humanos, o que paradoxalmente contribui para a afirmação desses Direitos. É na violação que os Direitos Humanos são confirmados e assim também acentuados na comunicação.

Estamos em um modelo de sociedade hipercomplexa onde as questões precisam ser pensadas como possíveis e impossíveis, sendo e não sendo. As questões apontam problemas paradoxais e precisam de respostas que observem criativamente esses paradoxos e consigam fazer a respectiva desparadoxação. A teoria dos sistemas é uma possibilidade de observação diferenciada das formas tradicionais do Direito e da sociedade.

Nesse sentido, busca criar as condições necessárias para se obter êxito nas ressonâncias produzidas no Direito. Trata-se de desenvolver a capacidade de produzir comunicação, a partir da compreensão da policontexturalidade social. Trata-se de uma perspectiva para se desenvolver uma operacionalização jurídica dinâmica e criativa em face das novas situações desencadeadas na sociedade complexa. É através do contraste das complexidades que também se pode identificar eventuais oportunidades para se provocar certa fissura na dogmática jurídica, observando pontos frágeis dos compartimentos normativos ao se deparar com situações inéditas, imprevistas, sem qualquer correspondência direta na legislação ou que corresponda uma violação dos Direitos Humanos.

As violações dos Direitos Humanos ocorrem na sociedade e muitas vezes, correspondem a um evento que pode estar sendo produzido por outros sistemas. As operacionalizações do sistema econômico, não raro colidem com Direitos Ambientais e Humanos. Não porque violar esses direitos seja o objetivo. Mas sim, porque as expectativas perseguidas pelo sistema econômico muitas vezes são incompatíveis com a expectativas de outros sistemas e por isso podem produzir efeitos colaterais para o Direito.

Por isso é importante o Direito observar essa complexidade de sistemas diferentes e suas respectivas comunicações. É assim que poderá produzir uma Decisão Jurídica que produza uma ressonância comunicativa em outros sistemas, estimulando formas de proceder (de acordo com sua auto-organização) que possam ser convergentes com a função do Direito na sociedade.

Significa dizer que pensar o Direito em face dessa complexidade social, significa

procuram aproximar aproximar a teoria luhmanniana da teoria kelseniana, ou requer acoplamentos estruturais, compatíveis com a autonomia e a clausura operativa dos sistemas. 
pensa-lo no mesmo espaço onde poderá haver colisões e cruzamentos de interesse de outros sistemas. O primeiro passo é desenvolver uma capacidade de observação da auto- organização social e poder identificar onde ocorrem as colisões nas operacionalizações dos diversos sistemas. O segundo passo é desenvolver uma boa observação da complexidade e a partir daí buscar desenvolver uma comunicação dos Direitos Humanos que produza efeitos eficazes para o Direito e consequentemente para a Sociedade.

\section{CONCLUSÃO}

Apesar de existirem grandes avanços no âmbito dos Direitos Humanos, tanto teóricos como práticos, isso não exclui a constatação simultânea de haver também uma grande gama de violações os Direitos Humanos e muitas produções teóricas que só ficam no plano acadêmico para cumprir exigências formais.

Nesse sentido, com a reflexão proposta, buscou-se indicar alguns pontos importantes, que iniciam com a observação de que certa radicalização na estabilização da produção epistemológica do Direito pode ser um obstáculo para a realização dos Direitos Humanos. Isso porque no Direito corrente, não raro, predomina uma postura excessivamente conservadora, que ficou conhecida como dogmática jurídica.

Essa postura além de atravessar todo o Direito, também dificulta a possibilidade de mudanças mais sofisticadas e rápidas no universo jurídico. Apresenta certa resistência que foi considerada a partir da ideia de uma Armadura Dogmática do Direito. Isso, como uma armadura sugere, corresponde a uma postura que se identifica excessivamente com o passado, que se mostra pesada e torna os processos e as decisões lentas. Se constitui em uma forma de operacionalização muito conservadora e por vezes defasada, não por falta de conhecimento, mas por impedir que conhecimentos já desenvolvidos em outras áreas penetrem os limites dessa armadura jurídica, como possibilidade de alguma contribuição evolutiva.

O que se observa com isso é que se os conhecimentos já desenvolvidos em outras áreas fossem integrados às reflexões jurídicas, poderiam problematizar drasticamente a produção teórica e prática do Direito. Bachelard dá um pequeno e relevante passo para contribuir para essa observação.

A dogmática jurídica produz formas de operacionalizar o Direito, mas também de torna-lo lento e defasado. Assentada em forte racionalidade moderna, a partir de pressupostos 
positivistas e normativistas, a dogmática jurídica produz diversos obstáculos epistemológicos. Esses obstáculos afetam o Direito como um todo. Sugere uma crise epistemológica generalizada. Apesar de que muitos teóricos que estudam os Direitos Humanos já tenham superado essas pesquisas, desenvolvendo trabalhos críticos, é na operacionalização do Direito Corrente, que os Direitos Humanos devem ser considerados. Justamente onde há certo predomínio da dogmática jurídica e por sua vez, decisões insuficientes para responder juridicamente às demandas de uma Sociedade Complexa. Isso pode ser observado em todos os âmbitos do Direito, inclusive em questões que afetam direta ou indiretamente a realização dos Direitos Humanos como um todo.

Assim, para evitar esses problemas e poder desenvolver uma observação diferenciada, buscando novas estratégias para a realização dos Direitos Humanos, busca-se a superação dos obstáculos epistemológicos excessivamente dogmáticos do Direito. Essa observação possibilitada pela contribuição de Bachelard abre uma perspectiva para outras observações da complexidade muitas vezes negada. Para tanto, transcender as limitações de uma epistemologia jurídica moderna, pressupõe considerar outras epistemologias.

$\mathrm{Na}$ perspectiva do trabalho, indica-se uma epistemologia construtivista de caráter sociológico, que pode acentuar as possibilidades de reconstrução dos contornos do Direito, conforme a observação e mudança do contexto social altamente complexo. Isso porque essa perspectiva epistemológica permite compreender melhor as peculiaridades do contexto social, que por sua vez revela interesses incompatíveis com os Direitos Humanos. É a prevalência de um desses interesses, dos mais diversos sistemas sociais que podem ser uma das causas de muitas violações dos Direitos Humanos. Muitas vezes as expectativas produzidas no sistema econômico ou mesmo políticos, se mostram contrários às expectativas produzidas, em especial no âmbito dos Direitos Humanos.

Por isso se torna relevante uma perspectiva na linha de um construtivismo sistêmico para os Direitos Humanos, pois além de possibilitar o requestionamento de teorias e práticas tradicionalmente adotadas no busca por proteção e garantia dos Direitos Humanos, também possibilita o desenvolvimento de uma observação diferente, o que por sua vez, pode possibilitar a construção de novas estratégias para ampliar as possibilidades de realização dos Direitos Humanos em toda a operacionalização jurídica, independente da importância e do respectivo ramo do Direito.

Nesse sentido, uma epistemologia que contemple uma observação da sociedade 
complexa, permite buscar compreender as possibilidades de colisões de eventuais expectativas advindas de sistemas sociais diferentes. Com isso, se pode agregar no Direito, elementos para a produção de uma comunicação dos Direitos Humanos que, de fato alcance uma maior eficácia na ressonância desses direitos em todos os sistemas sociais. Isso pode permitir que muitas das expectativas que sejam incompatíveis ou possam colidir e significar uma violação dos Direitos Humanos sejam equacionadas de forma convergente a fim de reforçar as possibilidades de realização dos Direitos humanos em uma perspectiva policontextural.

\section{REFERÊNCIAS}

BACHELARD, Gaston. A formação do espírito científico: contribuição para uma psicanálise do conhecimento. Rio de Janeiro: Contraponto, 1996.

BOBBIO, Norberto. A era dos direitos. Rio de Janeiro: Elsevier, 2004.

CAPRA, Fritjof. As conexões ocultas: ciência para uma vida sustentável. Tradução de Marcelo Brandão Cipolla, São Paulo: Cultrix, 2002.

COMPARATO, Fábio Konder. A afirmação histórica do Direitos Humanos. 7 ed. São Paulo: Saraiva, 2010.

. Fundamento dos Direitos Humanos. São Paulo: IEA, 1997. Disponível em:

<www.iea.usp.br/artigos>. Acessado em: 7, out., 2016

CORSI, Giancarlo; BARALDI, Cláudio; ESPÓSITO, Elena. Glosario sobre la teoria social de Niklas Luhmann. Tradução de Miguel Romero Pérez y Carlos Villalobos. Universidad Iberoamericana. Guadalajara, México: Diseño y Letras, S.A, 1996. DINIZ, Antonio Carlos; MAIA, Antônio Cavalcanti. Pós-Positivismo. In: BARRETO, Vicente de Paulo (Coord.). Dicionário de Filosofia do Direito. São Leopoldo: EDITORA UNISINOS, 2006.

FLORES, Luis Gustavo Gomes. Resiliência Jurídica: para pensar a inovação do Direito a partir de uma perspectiva sistêmica. 2014. 288f. Tese (Doutorado em Direito).- Programa de Pós-graduação em Direito, Universidade do Vale do Rio dos Sinos - UNISINOS, São Leopoldo, 2014.

GONZÁLEZ, Rodrigo Stumpf. Direitos Humanos na América Latina: transições 
Inconclusas e a Herança das Novas Gerações.

HOBSBAWM, Eric. Era dos Extremos: o breve século XX (1914-1991). JULIOS-CAMPUZANO, Alfonso de. Constitucionalismo em Tempos de

Globalização. Tradução de Jose Luis Bolzan de Morais e Valéria Ribas do Nascimento. Porto Alegre: Livraria do Advogado, 2010.

KELSEN, Hans. Teoria pura do direito. Tradução de João Baptista Machado, 7. ed.

São Paulo: Martins Fontes, 2006.

LUHMANN, Niklas. A improbabilidade da comunicação. 3 ed. São Paulo: Veja, 2001.

Introdução à Teoria dos Sistemas: Aulas publicadas por Javier Torres

Nafarrate. Petrópolis: Vozes, 2009.

. Sociologia do Direito II. Tradução de Gustavo Bayer. Rio de Janeiro: Tempo Brasileiro, 1985.

; DE GEORGI, Raffaele. Teoria de la sociedad. Tradução de Miguel Romero

Pérez y Carlos Villalobos. Universidad Iberoamericana. Guadalajara, México:

Universidade de Guadalajara, 1993.

. Introdução à Teoria dos Sistemas: Aulas publicadas por Javier Torres

Nafarrate. Petrópolis: Vozes, 2009.

MANSILLA, Dario Rodriguez; NAFARRATE, Javier Torres. Introducción a lá teoría de la sociedad de Niklas Luhmann. México: Herder, 2008.

MATURANA, Humberto. O que se observa depende do observador. In: THOMPSON,

W. I. (org.). GAIA: Uma teoria do conhecimento. São Paulo: Editora Gaia, 2000, p. 61.

MOREIRA, Marco Antonio; MASSONI, Neusa Teresinha. Epistemologias do Século

XX. São Paulo: E.P.U., 2011.

MORIN, Edgar. Educação e complexidade: Os sete saberes e outros ensaios. Tradução de

Edgard de Assis Carvalho. São Paulo: Cortez, 2002.

NEVES, Marcelo. Transconstitucionalismo. São Paulo: Martins Fontes, 2009.

NICOLESCU, Basarab. O Manifesto da Transdisciplinaridade. São Paulo: Triom, 2005.

PIOVESAN, Flávia. Direitos humanos e o direito constitucional Internacional.14. ed.

São Paulo: Saraiva, 2013. 
Direitos Humanos: desafios e perspectivas contemporâneas. Rev. TST, Brasília, vol. 75, no 1, jan/mar 2009 .

ROCHA, Leonel Severo; PEPE, Albano Marcos Bastos. Genealogia da Crítica

Jurídica: de Bachelard a Foucault. Porto Alegre: Verbo Jurídico, 2007.

Epistemologia Jurídica e Democracia. São Leopoldo: Ed. UNISINOS, 2003.

SUPIOT, Alain. Homo Jurídicus: ensaio sobre a função antropológica do Direito. São

Paulo: Martins Fontes, 2007.

TEUBNER, Gunther. O Direito como Sistema Autopoiético. Tradução de José

Engracia Antunes. Lisboa: Fundação Calouste Gulbenkian, 1989.

WARAT, Luis Alberto. Saber crítico e senso comum teórico dos juristas. In:

Epistemologia e Ensino do Direito: o sonho acabou. v. 2, Florianópolis: Fundação

Boiteux, 2004. 